\title{
Experimental determination of length changes of autoclaved aerated concrete during the freeze-thaw cycle
}

\author{
Radoslav Sovják ${ }^{1, *}$, Jiři Maděra ${ }^{2}$ \\ ${ }^{1}$ Experimental Centre, Faculty of Civil Engineering, Czech Technical University in Prague, \\ Thákurova 7, 16629, Prague, Czech Republic \\ ${ }^{2}$ Departmrnt of Materials Engineering and Chemistry, Faculty of Civil Engineering, Czech Technical \\ University in Prague, Thákurova 7, 16629, Prague, Czech Republic
}

\begin{abstract}
The aim of the paper is an experimental determination of the longitudinal expansion of autoclaved aerated concrete (AAC) during the freeze-thaw cycle. Longitudinal changes were measured with lasers and the surface temperature was measured using an infrared temperature gauge. The temperature distribution over the sample was verified by a numerical calculation.
\end{abstract}

\section{Introduction}

Building materials and structures are subjected to a number of climate cycles. Many buildings might become damaged soon after their completion or later after many repetitions of climate actions or as a result of synergies with other physical or chemical effects. Typical defects are cracking of finishes and spalling of surfaces. Many authors agree that mechanisms responsible for such failures are usually associated with length or volume changes of porous materials due to increased moisture content or temperature changes [1]. Several research studies have been conducted on the expansion of the hardened concrete [2], porous calcareous rock [3] or concrete with fine recycled aggregate [4] at different freezing and thawing temperatures. Autoclaved aerated concrete (AAC) was investigated by Trong et al. [5] who studied sorption isotherm and length change behaviour. The experimental results showed that the expansion of AAC during the adsorption process is mostly larger than the shrinkage in the first desorption process even though the water content in the adsorption process is lower.

\section{Experimental program}

Autoclaved aerated concrete with a bulk density of $300 \mathrm{~kg} / \mathrm{m}^{3}$ was investigated in this study. AAC is generally manufactured by autoclaving a mixture of finely ground silica materials, Portland cement, quicklime, water, gypsum, and an expanding agent, which is further cured under high temperature and saturated steam pressure [5]. In the framework of

*Corresponding author: sovjak@fsv.cvut.cz 
this study, one part of specimens was immersed into the water prior to the testing and the second part of specimens was cured in ambient temperature and humidity $\left(21{ }^{\circ} \mathrm{C}\right.$, $50 \% \mathrm{RH})$. All specimens were subjected to a temperature of $-30{ }^{\circ} \mathrm{C}$ for 24 hours and subsequently placed in the measurement unit under ambient temperature and humidity $\left(21^{\circ} \mathrm{C}, 50 \% \mathrm{RH}\right)$. All specimens were $210 \mathrm{~mm}$ in length, $40 \mathrm{~mm}$ in height and $20 \mathrm{~mm}$ in depth.

The common principle of using laser sensor for dilatation measurement was utilized for the monitoring of the expansion (Figure 1). The sensors measured distance without contact against a front surface of the specimen. The AAC specimen was placed between two lasers sensors on the special stainless-steel mount developed for the purpose of this study [6] (Figure 2). Measuring range of laser sensors was $5 \mathrm{~mm}$. Lasers worked with resolution $0.01 \%$ of full-scale output. Measuring rate of laser sensors was $1.5 \mathrm{kHz}$. The weight of the specimen was determined on the digital weight with $0.01 \mathrm{~g}$ accuracy.

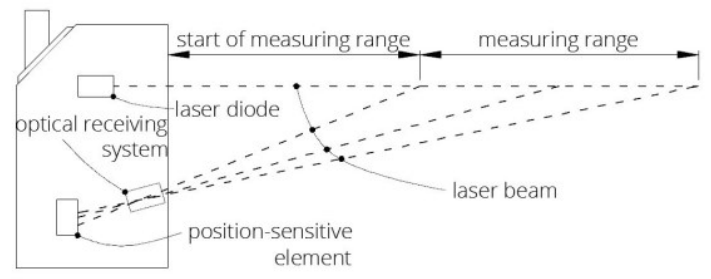

Fig. 1. The principle of the laser sensor.

Laser triangulation displacement sensor operated with a laser diode which projected a visible light spot onto the surface of the measurement target. Triangulation means the measurement of the distance by calculating the angle. The light reflected from the spot was imaged by an optical receiving system onto a position-sensitive element. If the light spot changed its position, this change was imaged on the receiving element and evaluated. Laser sensor used a semiconductor laser with a wavelength of $670 \mathrm{~nm}$. The maximum optical output power was $1 \mathrm{~mW}$. The sensor was classified as laser class II.

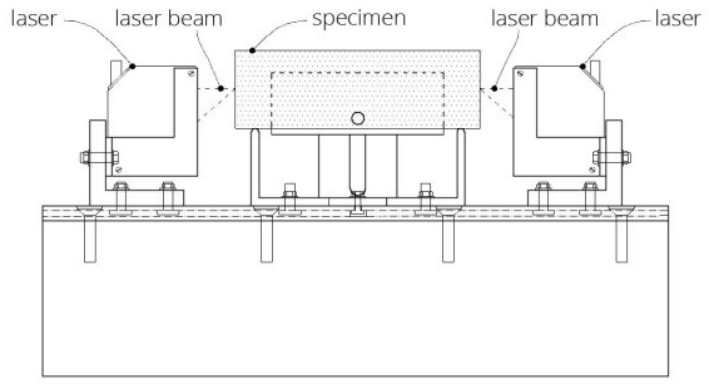

Fig. 2. Measurement unit.

The laser beam was strongly bundled using a special lens design in order to detect only a few micrometres in diameter on the measuring object. This was a particular benefit in the case of very small measuring objects. Even when measurements on structured surfaces are required, the small spot size is often advantageous. Basic characteristics of the laser triangulation displacement sensor used in this study are shown in Table 1. The sampling frequency of the laser sensor was set to $83.3 \mathrm{mHz}$. 
Table 1. Basic parameters of the laser sensor.

\begin{tabular}{|l|c|}
\hline Measuring range & $5 \mathrm{~mm}$ \\
\hline Start/end of measuring range & $20 / 25 \mathrm{~mm}$ \\
\hline Operation temperature & $0 \ldots+50^{\circ} \mathrm{C}$ \\
\hline Operation relative humidity & $5 \ldots 95 \%$ \\
\hline Measuring rate & $1.5 \mathrm{kHz}$ \\
\hline Resolution-static & $0.6 \mu \mathrm{m}$ \\
\hline
\end{tabular}

\section{Numerical analysis}

Numerical analysis of the temperature distribution over the cross-section of the sample was determined by using modified Künzel's mathematical model [7], which was further extended by effective specific heat capacity including ice formation in the material. Basic balance equations yields:

$$
\begin{aligned}
& c_{e f f} \rho_{v} \frac{\partial T}{\partial t}=\operatorname{div}(\lambda \operatorname{grad} T)+L_{v} \operatorname{div}\left(\delta_{p} \operatorname{grad} p_{v}\right) \\
& {\left[\rho_{w} \frac{d w}{d p_{v}}+(n-w) \frac{M}{R T}\right] \frac{\partial p_{v}}{\partial t}=\operatorname{div}\left[D_{g} \operatorname{grad} p_{v}\right]}
\end{aligned}
$$

where $c_{\text {eff }}\left(\mathrm{J} \cdot \mathrm{kg}^{-1} \cdot \mathrm{K}^{-1}\right)$ is the enthalpy density, $\rho_{v}\left(\mathrm{~kg} \cdot \mathrm{m}^{-3}\right)$ is the bulk density, $T(\mathrm{~K})$ is the absolute temperature, $\lambda\left(\mathrm{W} \cdot \mathrm{m}^{-1} \cdot \mathrm{K}^{-1}\right)$ is the thermal conductivity, $\mathrm{L}_{\mathrm{v}}\left(\mathrm{J} \cdot \mathrm{kg}^{-1}\right)$ is the latent heat of evaporation of water, $\delta_{p}(\mathrm{~s})$ is the water vapor diffusion permeability, $p_{v}(\mathrm{~Pa})$ is the partial pressure of water vapor in the porous space, $\rho_{w}\left(\mathrm{~kg} \cdot \mathrm{m}^{-3}\right)$ is the density of water, $w$ $\left(\mathrm{m}^{3} \cdot \mathrm{m}^{-3}\right)$ is the moisture content by volume, $n(-)$ is the porosity of the porous body, $M$ $\left(\mathrm{kg} \cdot \mathrm{mol}^{-1}\right)$ is the molar mass of water vapor, $R\left(\mathrm{~J} \cdot \mathrm{K}^{-1} \cdot \mathrm{mol}^{-1}\right)$ is the universal gas constant, and $D_{g}(\mathrm{~s})$ is the global moisture transport function. Basic material parameters for AAC [8] are shown in Table 1.

Table 2. Material parameters for AAC [8].

\begin{tabular}{|l|c|}
\hline Parameters & AAC \\
\hline Bulk density $\rho\left(\mathrm{kg} \cdot \mathrm{m}^{-3}\right)$ & 304 \\
\hline Open porosity $\psi(\%)$ & 86.9 \\
\hline Specific heat capacity $c\left(\mathrm{~J} \cdot \mathrm{kg}^{-1} \cdot \mathrm{K}^{-1}\right)$ & 1090 \\
\hline Water vapor diffusion resistance factor $\mu_{\text {dry }}(-)$ & 15.61 \\
\hline Water vapor diffusion resistance factor $\mu_{\text {sat }}(-)$ & 6.17 \\
\hline Thermal conductivity $\lambda_{\text {dry }}\left(\mathrm{W} \cdot \mathrm{m}^{-1} \cdot \mathrm{K}^{-1}\right)$ & 0.071 \\
\hline Thermal conductivity $\lambda_{\text {sat }}\left(\mathrm{W} \cdot \mathrm{m}^{-1} \cdot \mathrm{K}^{-1}\right)$ & 0.548 \\
\hline Apparent moisture diffusivity $\kappa\left(\mathrm{m}^{2} \cdot \mathrm{s}^{-1}\right)$ & $7.02 \times 10^{-8}$ \\
\hline
\end{tabular}

The problem was solved by using SIFEL [9], an open source computer code with a mesh with 6171 nodes and 5000 elements (Figure 3). Distribution of the temperature over the specimen is depicted in Figure 3. 


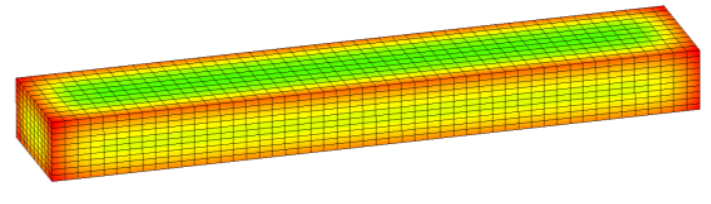

(a)

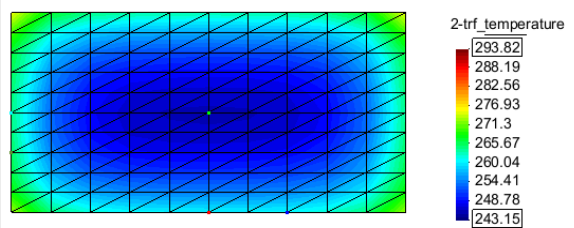

(b)

Fig. 3. Distribution of the temperature in the Kelvin scale over the dry specimen; (a) view of the whole specimen, (b) cross-section in the mid-span.

The initial moisture water content of the samples that were cured in the ambient temperature and humidity was determined to be $0.005 \mathrm{~m}^{3} / \mathrm{m}^{3}$, while the moisture water content of the specimens that were immersed in the water was determined to be $0.324 \mathrm{~m}^{3} / \mathrm{m}^{3}$.

\section{Results and discussion}

The surface temperature was measured using an infrared temperature gauge at regular time intervals (Figure 4). Temperature readings were coupled with the length changes gained from the lasers.

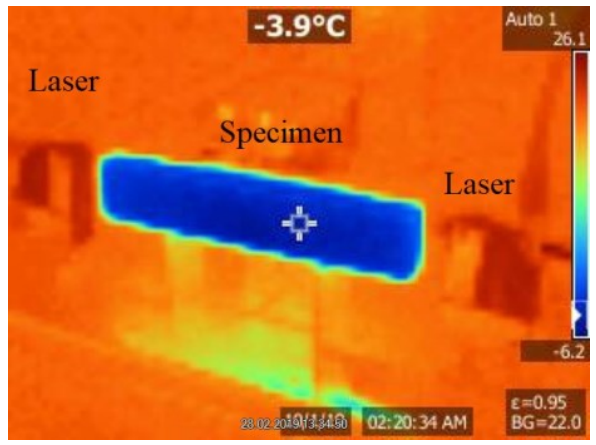

Fig. 4. Measurement of the surface temperature of the specimen.

The specimens that were cured in ambient temperature and humidity performed an increase in the length as the temperature of the specimen increases (Figure 5a). The specimens that were immersed in the water prior to the testing performed, apparently, different behaviour due to the high amount of water that was absorbed by the specimens. After the initial length increase, the specimen shrinks as the frozen water in the specimens starts to thaw (Figure 5b).

The final dilatation of the dry specimens was in the rage from $2.1 \times 10^{-4}$ to $2.8 \times 10^{-4}$ after 60 minutes in the ambient laboratory conditions. The final dilatation of the wet specimens was in the range from $2.4 \times 10^{-4}$ to $5.6 \times 10^{-4}$ after 120 minutes in the ambient laboratory conditions. The end of the measuring interval was set when the dilatation of the sample was constant. Herewith, the average overall dilatation of the sample was determined to be $4 \times 10^{-4}$ and $2.5 \times 10^{-4}$ for the wet and dry specimens, respectively. 


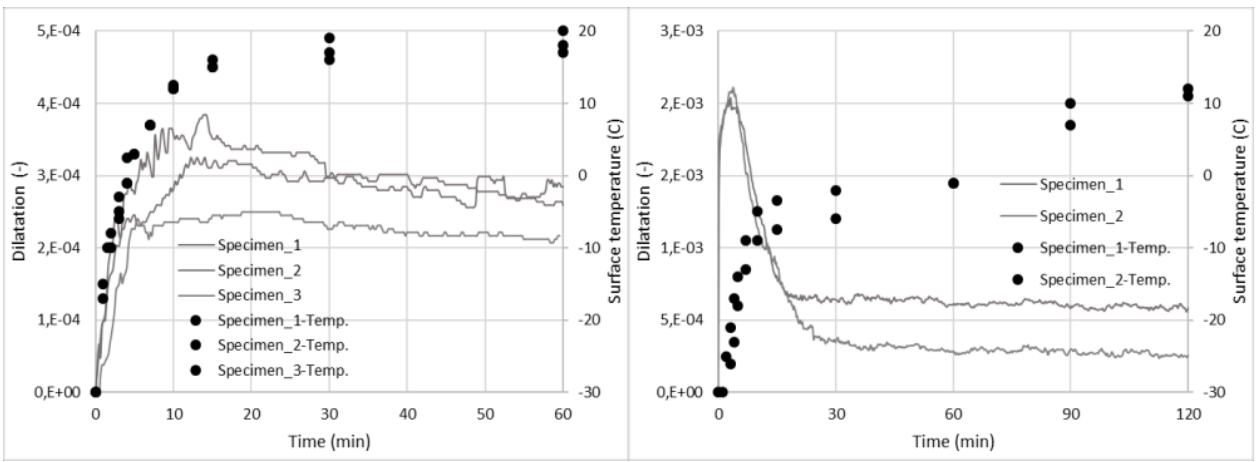

(a)

(b)

Fig. 5. Development of dilatation and surface temperature;

(a) the dry specimen, (b) the wet specimen.

The results of the numerical analysis for both humidity states are shown in Figure 6. The figures show a good agreement between the measured surface temperature of the sample from the experiment and the surface temperature obtained from the numerical analysis (red curve). The blue line shows the temperature development in the middle of the specimen.

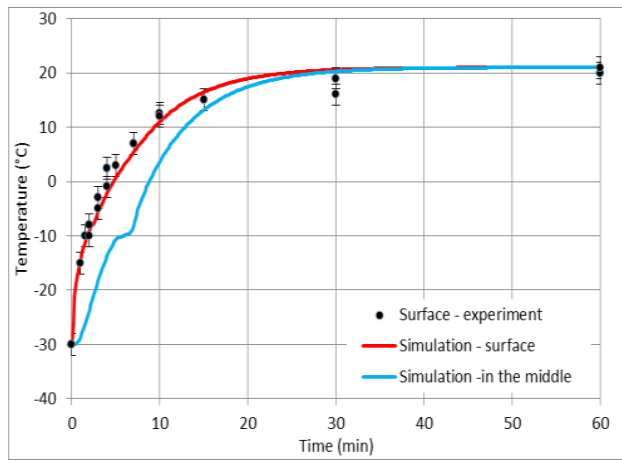

(a)

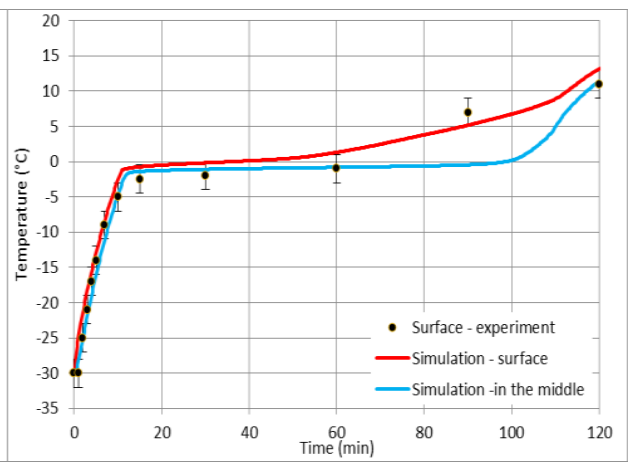

(b)

Fig. 6. Comparison of surface temperature obtained from experiment and from simulation;

(a) the dry specimen, (b) the wet specimen.

The results from measurements for relatively dry specimens and from numerical simulation show that even at such low humidity, ice melting can occur at very low temperatures (Fig. $6 \mathrm{a},-10^{\circ} \mathrm{C}$ ). Based on the rapid increase in dilatation in the first few minutes (Fig. 5a), we assume that the ice formation was initiated when samples were transported from the climatic chamber to the measuring unit. The water in the pores could only be subcooled, and this impulse gave rise to crystallization nuclei. Subsequent reduction of dilatation may be attributed to the melting of ice. The elongation at the end of the measuring interval corresponds to a material dilatation. The wet specimen shows an even larger and faster increase in dilatation strain in the first few minutes. It can be assumed that this is the same effect only with a larger volume of pores with subcooled water. On the basis of a numerical simulation, it can be stated that the measurement for this humidity state was terminated prematurely because the temperature inside the specimen did not reach the ambient temperature. 


\section{Conclusions and further outlook}

A simple experimental procedure for the determination of the dilatation of the specimen was proposed in order to evaluate a dilatation of the autoclaved aerated concrete. Two humidity states (dry a wet specimen) were studied and overall dilatation of the AAC specimens was derived.

Based on the first set of measurements and on the basis of the information obtained, more sets of measurements depending on the humidity including a completely dry specimen should be carried out. The measuring interval for relatively wet specimens should be terminated with respect to the temperature in the middle of the specimen.

In future research, more specimens are recommended to be tested for temperature dilatation. Also, various types of AAC with different bulk density should be involved in the experimental program.

The authors greatly acknowledge the financial support of the Czech Science Foundation under project No. 17-01365S. The authors also acknowledge the assistance from the technical staff at the Experimental Centre, Faculty of Civil Engineering, Czech Technical University in Prague; and students who participated in the project.

\section{References}

1. Baker, M.C., 1964, Thermal and moisture deformations in building materials, Canadian Building Digest, 56, p. 1-4.

2. Johannesson, B., 2010, Dimensional and ice content changes of hardened concrete at different freezing and thawing temperatures, Cement and Concrete Composites, 32 (1), p. $73-83$.

3. Prick, A., 1995, Dilatometrical behaviour of porous calcareous rock samples subjected to freeze-thaw cycles, CATENA, 25 (1-4), p. 7-20.

4. Bogas, J.A., de Brito, J. and Ramos, D., 2016, Freeze-thaw resistance of concrete produced with fine recycled concrete aggregates, Journal of Cleaner Production, 115, p. 294-306.

5. Nguyen Trong, L., Asamoto, S. and Matsui, K., 2018, Sorption isotherm and length change behavior of autoclaved aerated concrete, Cement and Concrete Composites, 94, p. 136-144.

6. Sovják, R., Korecký, T. and Gundersen, A., 2015, An experimental investigation into moisture-induced expansion of plasters, Acta Polytechnica, 55 (3), p. 187.

7. Kočí, J., Maděra, J. and Černý, R., 2018, Formulation of a hygrothermal model for description of ice-forming process in porous building materials, AIP Conference Proceedings,vol. 2040.

8. Jerman, M., Keppert, M., Výborný, J. and Černý, R., 2013, Hygric, thermal and durability properties of autoclaved aerated concrete, Construction and Building Materials, 41(1), p. 352-359.

9. Krejčí T., Koudelka T. and Kruis J., 2011, Modelling of Building Constructions in SIFEL Environment, 1. ed. Praha: České vysoké učení technické v Praze, 2011. 87 p. ISBN 978-8001-04930-3. 